\title{
Nucleated red blood cells as predictor of all-cause mortality in emergency department
}

\author{
Hüseyin $\mathrm{Narcl}^{\mathrm{a}, *}$, Mehmet Murat Oktay ${ }^{\mathrm{b}}$, Cüneyt Ayrik ${ }^{\mathrm{c}}$, Mehmet Burak Yavuz Çimen ${ }^{\mathrm{d}}$ \\ ${ }^{a}$ Mersin University, Faculty of Medicine, Department of Emergency Medicine, Mersin, Turkey \\ ${ }^{\mathrm{b}}$ Hasan Kalyoncu University, Vocational High School,Turkey, Gaziantep, Turkey \\ c Mersin University, Faculty of Medicine, Department of Emergency Medicine, Mersin, Turkey \\ d Department of Biochemistry, Mersin University Medical Faculty, Mersin, Turkey
}

\section{A R T I C L E I N F O}

\section{Article history:}

Received 9 September 2020

Received in revised form 1 October 2020

Accepted 2 October 2020

Available online $\mathrm{xxxx}$

\section{Keywords:}

Nucleated red blood cells

Mortality

Emergency department

\begin{abstract}
A B S T R A C T
Bacground: Nucleated red blood cells (NRBCs) are immature erythrocytes that are not normally detected in the blood of healthy adults. The detection of these cells in peripheral blood is associated with increased mortality and poor prognosis. In this study, we aimed to investigate whether NRBCs predict for all causes of death in patients admitted to the emergency department (ED).

Method: This study was conducted retrospectively between January 2019 and December 2019 in academic emergency department, faculty of medicine. We included all patients who died of non-traumatic causes and The control group consisted of patients discharged from the ED. NRBCs and other laboratory parameters were compared between the two groups. The primary outcome is all-cause mortality in the ED. Multivariate logistic analysis was performed.

Results: A total of 204 patients (119 male) were included in the study. The mean age of the patients was $66.7 \pm 14.6$ years. NRBC value was higher in those who died $(678.43 \pm 655.16 / \mu \mathrm{l})$ compared to the control group $(22.55 \pm 57.86 / \mu \mathrm{l})(P<0.001)$. According to receiver operating characteristic curve analysis (ROC) performed for the prediction all cause mortality in the ED, the best cut-off point for NRBC was $>0 / \mu \mathrm{l}$ (sensitivity $94,12 \%$, specificity $82,35 \%$, Area Under Curve (AUC) $=0.97$ ). In the multivariate logistic regression analysis, the $\mathrm{NRBC}$ was associated with all-cause mortality in the $\mathrm{ED}$ (odds ratio, $\mathrm{OR}=1.020$, confidence interval, $\mathrm{CI}=1.012-1.028$ ).

Conclusions: High blood levels of nucleated red blood cells at admission to the emergency department may be associated with increased mortality.
\end{abstract}

(c) 2020 Elsevier Inc. All rights reserved.

\section{Introduction}

Nucleated red blood cells (NRBCs) are precursor cells of the erythropoietic series and are not found in circulation in healthy adults, their detection in peripheral blood is associated with increased mortality and poor prognosis. They appear in peripheral blood in cases of hematopoietic stress, such as inflammation, massive bleeding, hematological cancer, extramedullary hematopoiesis or severe hypoxia [1,2].

Recently, studies have investigated the relationship between critically ill patients and NRBCs levels. In these studies, it was emphasized that routine analysis of NRBCs in critically ill patients may be effective in predicting mortality. Prolonged hospital stay and increased mortality were found to be related to NRBCs levels. Furthermore, in admission to intensive care unit (ICU), the NRBCs values were indicated to be an independent risk factor for mortality [1-4].

\footnotetext{
* Corresponding author

E-mail address: hsnnarci@gmail.com (H. Narc1).
}

This marker may be useful in identifying patients at high risk of mortality presenting to the ED. To the best of our knowledge, we have not found any study investigating the relationship between mortality and nucleated red blood cells in ED patients. Therefore, we hypothesized that NRBCs blood levels may be high in patients who died in the early period (first $24 \mathrm{~h}$ ) admitted to ED.

In this study, we tried to investigate whether NRBCs predict mortality in patients admitted to the ED.

\section{Materials and method}

\subsection{Patients and study design}

This present retrospective study was conducted between January 2019 and December 2019 at Mersin University Hospital, a tertiary academic Emergency Medicine Department. Our ED serves approximately 100,000 patients a year. The study was conducted by retrospectively analyzing all data from the hospital's electronic information operating 
system. Approval was obtained from the Ethics Committee dated 19/08/ 2020 and numbered 594/17 for the study.

Patients whose laboratory data were not available, those with hematological disease, patients with cancer, patients under the age of 18 , immunosuppressive patients, trauma patients, those who received chemotherapeutic drugs and corticosteroid therapy were not included in the study. A total of 120 cases who died were found eligible and enrolled in the present study, and 18 cases were excluded and the study was completed with 102 cases. In addition, 102 patients who applied to ED were included in the study as a control group. The control group consisted of patients who had no serious illnesses and who met exclusion criteria. Finally, the data of 204 cases were analysed. Patients' ages, genders, leukocyte, haemoglobin, red cell distribution width (RDW), nucleated red blood cells (NRBC), platelet-large cell ratio (PLCR) and CRP values were recorded in the study form. All parameters were statistically compared between deceased and control groups.

\subsection{Laboratory examination}

After blood was taken into an EDTA tube for the determination of leukocyte, $\mathrm{Hb}, \mathrm{RDW}, \mathrm{NRBC}$ and P-LCR, the measurement was made on the otoanalyzer (XN-1000, Sysmex Corp. Kobe, JAPAN). Normal reference values of the parameters in our study were as follows: leukocyte (4500-11,000 /mm3), Hb (12.6-17.4 g/dl), RDW (11.6-14.8\%), NRBC (30-110/ $/ \mathrm{l})$, PLCR (\%), serum CRP (0-5 mg / L).

\subsection{Statistical analysis}

Normality controls of continuous measurements were tested with Shapiro Wilk test. For group comparisons of continuous measurements, Student's $t$-test was used for normally distributed data and Mann Whitney $U$ test was used for data that did not show normal distribution. Mean and standard deviation values are given as descriptive statistics. Pearson's chi-square test was used for the analysis of categorical data. Univariate logistic regression analysis was performed to determine the factors affecting thedeaths. Significant ones (leukocyte, NRBC, PLCR, $\mathrm{RDW}, \mathrm{Hb}, \mathrm{CRP}$ ) in univariate analyzes were tested by Multivariate Logistic regression analysis. In addition, ROC analyzes were used to determine the cut-off points of continuous variables. Number and percentage values are given as descriptive statistics. Statistical significance was taken as $p<0.05$.

\section{Results}

A total of 204 patients, 119 (58.3\%) male and 85 (41.7\%) female, were included in the study. The mean age of the patients were $66.7 \pm$ 14.6 years. When the distribution of causes of death in the emergency department is examined; It was found to be due to cardiovascular (37.2\%), pulmonary (13.7\%) and infective reasons (10.8\%), respectively (Table 1). NRBC value was higher in patients who died than in control group $(678.43 \pm 655.1 / \mu l, 22.55 \pm 57.86 / \mu l, p<0.001$. In addition, leukocyte, PLCR, RDW and CRP values were found to be statistically higher in the patients who died. There was no difference in $\mathrm{Hb}$ value between the two groups (Table 2).

Table 1

Distribution of causes of death in the emergency department

\begin{tabular}{lc}
\hline Cardiovascular & $38(37.2 \%)$ \\
Pulmonary & $15(14.8 \%)$ \\
Infection & $14(13.7 \%)$ \\
Neurological & $11(10.8 \%)$ \\
Cancer & $10(9.8 \%)$ \\
Gastrointestinal & $4(3.9 \%)$ \\
Other & $10(9.8 \%)$ \\
Total & $102(100 \%)$ \\
\hline
\end{tabular}

Table 2

Comparison of laboratory values between patients who died in the emergency department and the control group.

\begin{tabular}{llll}
\hline Parameters & $\begin{array}{l}\text { Dead }(\mathrm{n}=102) \\
(\text { Mean } \pm \text { SD })\end{array}$ & $\begin{array}{l}\text { Control }(n=102) \\
(\text { Mean } \pm \text { SD })\end{array}$ & P \\
\hline Age & $68,4 \pm 16.8$ & $65,0 \pm 11,9$ & 0,099 \\
Leucocyte & $12,988,82 \pm 4541,49$ & $8640,59 \pm 2477,85$ & $<\mathbf{0 , 0 0 1}$ \\
PLCR & $30,63 \pm 6,29$ & $28,45 \pm 6,95$ & $\mathbf{0 , 0 2 0}$ \\
Hb & $12,99 \pm 1,85$ & $12,83 \pm 1,44$ & 0,507 \\
RDW & $15,39 \pm 2,92$ & $14,29 \pm 2,13$ & $\mathbf{0 , 0 0 2}$ \\
NRBC & $678,43 \pm 655,16$ & $22,55 \pm 57,86$ & $<\mathbf{0 , 0 0 1}$ \\
CRP & $14,12 \pm 13,74$ & $6,86 \pm 6,23$ & $<\mathbf{0 , 0 0 1}$ \\
\hline
\end{tabular}

According to receiver operating characteristic curve analysis (ROC) performed for the prediction all cause mortality in the ED, the best cut-off point for NRBC was $>0 / \mu$, the sensitivity and specificity of $94.12 \%$, and $82.35 \%$ respectively, and positive and negative predictive values of $84.21 \%$ and $93.33 \%$, respectively: When the cut-off value for leukocyte value was $>10,330 / \mathrm{mm} 3$, the sensitivity was $76.47 \%$ and the specificity was $75.49 \%$. The specificity and sensitivity of RDW, PLCR, CRP and Hb values were found to be poorer. When the AUC values were examined, the highest value was found in NRBC (AUC $=0.947,(p$ $<0.001$ ). AUC values for leukocyte, CRP, RDW, PLCR, and Hb were 0.806 , 0.680, 0.620, 0.596 and 0.505, respectively (Table 3) (Fig. 1).

Univariate logistic regression analysis was performed to determine the factors affecting the deaths. In the univariate analysis, the following parameters were found to be statistically associated with mortality: leukocyte, NRBC, PLCR, RDW, Hb and CRP. According to the results of multivariate regression analysis using variables (Leukocyte, NRBC, PLCR, $\mathrm{RDW}, \mathrm{Hb}$ and $\mathrm{CRP}$ ) that were statistically significant in univariate analysis, it was determinated that high NRBC and leukocyte levels were found to be associated with increased mortality. The correct classification rate of the model was calculated as $92.2 \%$. Nucleated red blood cells $(\mathrm{OR}=1.020, \mathrm{CI}=1.012-1.028, p<0.001)$ and leukocyte $(\mathrm{OR}=$ $1.001, \mathrm{CI}=1000-1.001, p<0.001)$ parameters were observed to be independent variables predicting the deaths. There are 1.020 times more deaths for 1 unit increase in NRBC values ( $p<0.001$ ). Likewise, as the leukocyte values increase, 1.001 times more deaths occur $(p<0.001)$ (Table 4).

\section{Discussion}

To our knowledge, this study constitutes the most comprehensive review of the relationship between NRBCs and deaths in the ED. Our main finding, NRBC value was found to be an independent variable of all-cause deaths admitted to the ED. Nucleated red blood cells leukocyte, PLCR, RDW and CRP values were found to be higher in the patients who died. When the AUC values were evaluated in the ROC analysis, the highest AUC value was found in NRBC. In addition, the specificity and sensitivity of NRBC in distinguishing patients who died were $82.35 \%$ and $94.12 \%$, respectively.

NRBCs are normally observed in the peripheral blood of newborns and during pregnancy. In all other conditions, NRBC is accepted as a marker of severe stress or pathological erythropoiesis [5]. Systemic inflammation, hypoxia and massive bleeding, leading to an increase in erythropetic pressure, can lead to an increase in NRBC [6].

Stachon et al. revealed increased mortality in critical ill patients with elevated NRBC levels in peripheral blood. They also stated that NRBC showed $57.9 \%$ and $93.9 \%$ sensitivity and specificity for in-hospital mortality, respectively [3]. In another study, Menk et al. noted that increased mortality and prolonged hospitalization in patients with high concentration of NRBC. They also found that NRBC was an independent risk fac-

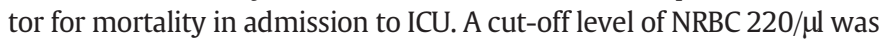
associated with more than three times the risk of ICU death [2]. Similarly, Purtle et al. stated that if the NRBC concentration is above $200 / \mu \mathrm{l}$ 
Table 3

Performance characteristics of laboratory parameters in determining mortality

\begin{tabular}{|c|c|c|c|c|c|c|}
\hline Parameters & Cut-off & $\begin{array}{l}\text { AUC } \\
(\mathrm{p})\end{array}$ & Sensitivity & Specificity & PPV & NPV \\
\hline Leucocyte & $>10,330$ & $\begin{array}{l}0,806 \\
(0,0001)\end{array}$ & $\begin{array}{l}76,47 \\
(67,0-84,3)\end{array}$ & $\begin{array}{l}75,49 \\
(66,0-83,5)\end{array}$ & $\begin{array}{l}75,73 \\
(66,29-83,63)\end{array}$ & $\begin{array}{l}76,24 \\
(66,74-84,14)\end{array}$ \\
\hline PLCR & $>29,4$ & $\begin{array}{l}0,596 \\
(0,0159)\end{array}$ & $\begin{array}{l}58,82 \\
(48,6-68,5)\end{array}$ & $\begin{array}{l}60,78 \\
(50,6-70,3)\end{array}$ & $\begin{array}{l}60,00 \\
(49,72-69,67)\end{array}$ & $\begin{array}{l}59,62 \\
(49,54-69,12)\end{array}$ \\
\hline $\mathrm{Hb}$ & $\leq 11,9$ & $\begin{array}{l}0,505 \\
(0,9084)\end{array}$ & $\begin{array}{l}37,25 \\
(27,9-47,4)\end{array}$ & $\begin{array}{l}74,51 \\
(64,9-82,6)\end{array}$ & $\begin{array}{l}59,38 \\
(46,37-71,48)\end{array}$ & $\begin{array}{l}54,29 \\
(45,66-62,72)\end{array}$ \\
\hline RDW & $>15,5$ & $\begin{array}{l}0,620 \\
(0,0021)\end{array}$ & $\begin{array}{l}40,20 \\
(30,6-50,4)\end{array}$ & $\begin{array}{l}83,33 \\
(74,7-90,0)\end{array}$ & $\begin{array}{l}70,69 \\
(57,27-81,90)\end{array}$ & $\begin{array}{l}58,22 \\
(49,78-66,32)\end{array}$ \\
\hline NRBC & $>0$ & $\begin{array}{l}0,947 \\
(0,0001)\end{array}$ & $\begin{array}{l}94,12 \\
(87,6-97,8)\end{array}$ & $\begin{array}{l}82,35 \\
(73,5-89,2)\end{array}$ & $\begin{array}{l}84,21 \\
(76,20-90,36)\end{array}$ & $\begin{array}{l}93,33 \\
(86,04-97,50)\end{array}$ \\
\hline CRP & $>9,6$ & $\begin{array}{l}0,680 \\
(0,0001)\end{array}$ & $\begin{array}{l}57,84 \\
(47,7-67,6)\end{array}$ & $\begin{array}{l}74,51 \\
(64,9-82,6)\end{array}$ & $\begin{array}{l}69,41 \\
(58,47-78,95)\end{array}$ & $\begin{array}{l}63,87 \\
(54,55-72,47)\end{array}$ \\
\hline
\end{tabular}

the mortality rate increases [4]. Likewise, Desai et al. reported that inhospital and ICU mortality rates increased with increasing NRBC concentration [7]. In our study, we found NRBCs to be an independent predictor of death in patients in the ED, and the NRBC value was found to be higher in patients who died $(678.43 \pm 655.16 / \mu \mathrm{l})$ than in the control group. In our study, the cut-off value of NRBC was $>0 / \mu l$. This means that NRBC does not exist in peripheral blood under normal conditions. This result corresponds exactly with the literature information. At such a cut-off value, the sensitivity and specificity of NRBC were found to be $82.35 \%, 94.12 \%$, respectively. The sensitivity and specificity values were found to be higher when compared with other markers. Also, among the parameters, the highest AUC value (0.947) was found in NRBC. According to these data, the use of NRBC may be appropriate to distinguish critical patients, especially in crowded emergency departments.

In emergency department patients, the mechanism of the relationship between NRBC and mortality is not fully understood. However, it has been reported in several publications that this condition is associated with severe hypoxia. In addition, the inflammatory response characterized by cytokine release may be associated with increased NRBC levels. Apart from erythropoietin(EPO), erythropoiesis is also regulated by the influence of various factors such as granulocyte macrophage colony stimulating factor, interleukins, tumor necrosis factor and glucocorticoids. The main source of EPO is kidney and its production is stimulated by hypoxia. Acute hypoxia can produce an erythropoietin response within $1.5 \mathrm{~h}$ [8-10]. As with the above mechanisms, it may be thought that the increased NRBC level in our patients who died may be due to hypoxic and systemic inflammation. Because if we assume that the vast majority of our patients die from cardiovascular and pulmonary causes, this hypothesis may be more likely to be correct. In addition, high CRP and leukocyte count, which are among the early indicators of acute phase response in cases with death in our study, support the role of inflammatory mediators in the production and release of nucleated red blood cells. Further research on this subject may be required to elucidate possible mechanisms.

The limitations of this study are that it is single center and retrospective. In addition, the causes of death in patients admitted to the emergency department were not considered separately. Therefore, we were unable to analyze the relationship between NRBC and causespecific mortality. The relationship between specific patient conditions

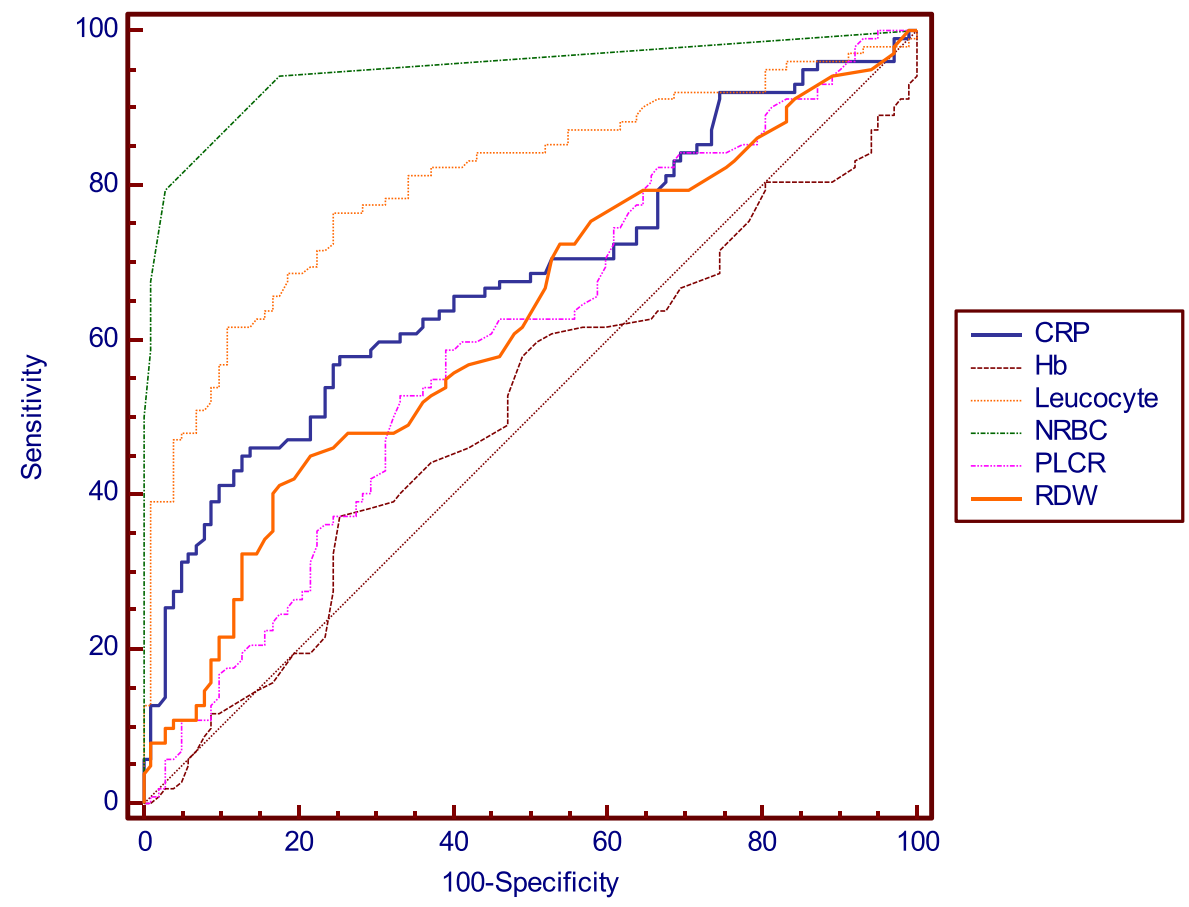

Fig. 1. Receiver-operating characteristics curve that shows the relationship between mortality and variables. 
Table 4

Multivariate Logistic regression analysis of variables for the prediction of mortality

\begin{tabular}{lllll}
\hline Variables & $\mathrm{B}$ & Wald & OR $(\% 95 \mathrm{CI})$ & $\mathrm{P}$ \\
\hline Leucocyte &, 001 & 18,765 & $\begin{array}{l}1001 \\
(1000-1001)\end{array}$ & $<\mathbf{0 , 0 0 1}$ \\
PLCR &, 087 & 3696 & $\begin{array}{l}1091 \\
(0,998-1191)\end{array}$ &, 055 \\
RDW &, 061 &, 251 & $\begin{array}{l}1063 \\
(0,838-1349)\end{array}$ &, 616 \\
NRBC &, 020 & 24,579 & $\begin{array}{l}1020 \\
(1012-1028)\end{array}$ & $<\mathbf{0 , 0 0 1}$ \\
CRP &, 004 &, 014 & 1004 &, 906 \\
& & & $(0,935-1078)$ & \\
\hline
\end{tabular}

and NRBC significance can be further explored and elaborated. Moreover, using a multicenter approach may be more beneficial for generalizability.

\section{Conclusions}

The presence of NRBC in peripheral blood may be an early predictor of death in patients admitted to the emergency department. This marker is routinely measured by analysis of hematological parameters and can therefore be used for further evaluation at no additional cost. This study should make clinicians think that the presence of NRBC in peripheral blood may be a predictor of all-cause death in patients admitted to EDs. These patients should be under close follow-up.

\section{Financial support and sponsorship}

Nil

\section{CRediT authorship contribution statement}

Hüseyin Narcl: Data curation, Formal analysis, Funding acquisition, Supervision, Validation, Visualization, Writing - original draft, Writing - review \& editing. Mehmet Murat Oktay: Conceptualization, Data curation, Formal analysis, Funding acquisition, Supervision, Validation. Cüneyt Ayrık: Conceptualization, Data curation, Formal analysis, Funding acquisition. Mehmet Burak Yavuz Çimen: Conceptualization,
Data curation, Formal analysis, Funding acquisition, Validation, Visualization, Writing - original draft, Writing - review \& editing.

\section{Declaration of Competing Interest}

There are no conflicts of interest.

\section{Acknowledgements}

The authors thank to Semra Erdoğan for the statistical analysis of this study.

\section{References}

[1] Stachon A, Holland-Letz T, Kempf R, Becker A, Friese J, Krieg M. Poor prognosis indicated by nucleated red bloodcells in peripheral blood is not associated with organ failure ofthe liver or kidney. Clin Chem Lab Med. 2006;44:955-61.

[2] Menk M, Giebelhäuser L, Vorderwülbecke G, Gassner M, Graw JA, Weiss B, et al. Nucleated red blood cells as predictors of mortality in patients with acute respiratory distress syndrome (ARDS): an observational study. Ann Intensive Care. 2018;8:42.

[3] Stachon A, Holland-Letz T, Krieg M. High in-hospital mortality of intensive care patients with nucleated red blood cells in blood. Clin Chem Lab Med. 2004;42:933-8.

[4] Purtle SW, Horkan CM, Moromizato T, Gibbons FK, Christopher KB. Nucleated red blood cells, critical illness survivors and postdischarge outcomes: a cohort study. Crit Care. 2017;21:154.

[5] Constantino BT, Rivera GKQ. Cutoff value for correcting white blood cell count for nucleated red blood cells: what is it? Why is it important? Lab Med. 2019;50: e82-90.

[6] Monteiro Júnior JGM, Torres DOC, da Silva MCFC, Martins CMH, Silva IK, Nascimento MEM, et al. Prognostic value of hematological parameters in patients with acute myocardial infarction: Intrahospital outcomes. PloS One. 2018;13(4):e0194897.

[7] Desai S, Jones SL, Turner KL, Hall J, Moore LJ. Nucleated red blood cells are associated with a higher mortality rate in patients with surgical sepsis. Surg Infect (Larchmt). 2012;13(6):360-5.

[8] Stachon A, Kempf R, Holland-Letz T, Friese J, Becker A, Krieg M. Daily monitoring of nucleated red blood cells in the blood of surgical intensive care patients. Clin Chim Acta. 2006;366:329-35.

[9] Frey B, Duke T, Horton SB. Nucleated red blood cells after cardiopulmonary bypass in infants and children: is there a relationship to the systemic inflammatory response syndrome? Perfusion. 1999;14:173-80.

[10] Krafte-Jacobs B, Bock GH. Circulating erythropoietin andinterleukin-6 concentrations increase in critically ill children with sepsis and septic shock. Crit Care Med. 1996;24:1455-9. 